\title{
Responsibility-Sensitive Healthcare Funding: Three Responses to Clavien and Hurst's Critique
}

THOMAS DOUGLAS ${ }^{1}$

University of Oxford

[This is a pre-publication version of Douglas T, 'Responsibility-Sensitive Healthcare Funding: Three Responses to Clavien and Hurst's Critique', Cambridge Quarterly of Healthcare Ethics 2020; 29(2): 192-195. The final published version is available here.]

${ }^{1}$ I would like to thank Rebecca Brown for comments on a draft of this article. I thank the Uehiro Foundation on Ethics and Education for their funding. 
Christine Clavien and Samia Hurst ${ }^{1}$ (henceforth C\&H) make at least three valuable contributions to the literature on responsibility and healthcare. They offer an admirably clear and workable set of criteria for determining a patient's degree of responsibility for her health condition; they deploy those criteria to cast doubt on the view that patients with lifestylerelated conditions are typically significantly responsible for their conditions; and they outline several practical difficulties that would be raised by any attempt to introduce responsibilitysensitive healthcare funding. I am sympathetic to the general thrust of their argument, share - at least tentatively - their policy conclusions, and was persuaded by much of the detail of their argument. However, I do have three critical comments.

\section{Type 1 Psychological Processes and Responsibility}

First, I believe that $\mathrm{C} \& \mathrm{H}$ are too swift in their treatment of rapid, automatic, 'type 1' psychological processes and the relevance of these processes to responsibility. In their discussion of their 'Condition 4', according to which responsibility depends on control, they treat type 1 processes as factors that limit control, and thus diminish responsibility, rather than as mechanisms via which we exercise control. It is presumably for this reason that, in Table 1, they classify '[s]trong gustatory pleasure for salt, sugar and fats' as a responsibility -mitigating factor.

This classification presupposes that type 1 processes are external to the autonomous agent or 'chooser' rather than being part of the way that the autonomous agent chooses. It is not clear, however, that this is always the case.

Consider a fictional character often discussed in philosophical moral psychology: Mark Twain's Huck Finn. In Chapter 16 of The Adventures of Huckleberry Finn, Huck, who is helping Jim, a slave, to escape to freedom, experiences pangs of conscience. ${ }^{2}$ Huck's explicit deliberation leads him conclude that he ought not to help Jim escape - that in doing so, he is collaborating in a wrong. He judges that he ought to abort the escape mission and turn Jim in, but something deep inside him - some barely conscious feeling of sympathy for Jimprevents him from doing so, and Huck ends up enabling Jim to reach his freedom.

C\&H's view seems to imply that Huck is not responsible, and thus not praiseworthy, for helping Jim to escape, since his helping is based on a type 1 process, not his explicit moral deliberation. But this is hard to accept. Surely Huck is praiseworthy. Indeed, it seems plausible to think that the fact that he has to overcome his (faulty) explicit moral deliberation to do the right thing makes him even more praiseworthy than he would otherwise have been.

More generally, it seems plausible to think that we can often be fully responsible, and thus highly praise- or blame-worthy, for actions that we do from rapid, automatic, and even 
subconscious processes. ${ }^{3}$ Yet this appears to be ruled out by C\&H's view of the relevance of type 1 processes to responsibility.

\section{Implications for Tort and Criminal Law}

A second worry about C\&H's argument concerns its possible implications beyond the sphere of healthcare. I am thinking, in particular, of its implications for criminal and tort law. C\&H's argument may seem to imply that many people whom most of us would think are morally liable to criminal punishment or compensatory damages are in fact not so-liable, since they are not responsible for the harmful outcomes that they (probably) cause.

Suppose that the owner of a small plumbing business negligently allows five of her employees to be exposed to very high levels of asbestos fibres; she fails to warn them that a work site is heavily contaminated with the substance and that protective measures are thus required. Suppose, further, that this exposure, in combination with a complex set of genetic predispositions and chance mutations, causes one of these employees to develop lung cancer later in life.

C\&H's argument may seem to have implausible implications regarding the employer's responsibility in this case. To bring this out, let me make three further stipulations. First, suppose that, though the asbestos exposure was certainly necessary for the development of the cancer, at least some of the genetic predispositions and mutations were necessary too, and the relative causal contribution of these factors is unclear. Second, suppose that the employer was - like most people ${ }^{4,5}$ — only vaguely aware of the relationship between asbestos exposure and cancer, and had no knowledge that the relationship was so strong. Third, suppose that the employer's decision to expose the workers was the result of a type 1 process: she was informed of the asbestos contamination while in the middle of dealing with a sick child, and just a few minutes before her employees were due to begin work; wanting to avoid further stress, she quickly dismissed the thought that she should warn her workers or call off the job.

Even with these further stipulations most of us would, I think, want to maintain that the employer is substantially responsible for the employee's cancer, but it is hard to see how $\mathrm{C} \& \mathrm{H}$ could accommodate this intuitive verdict. They seem committed to holding that the employer's responsibility is mitigated by fact that the employer is fundamentally responsible only for her action, not for the resulting bad outcome, and there is only an uncertain and complex causal connection between two (Condition 1), by the employer's lack of knowledge (Condition 3), and by the rapid and automatic nature of the psychological process leading to her failure to prevent the exposure (Condition 4).

More generally, I worry that C\&H's views may have radical - and, at least in some cases, intuitively unappealing - implications in many criminal and tort cases. I suspect their 
view will imply that many legal systems are currently punishing, or imposing compensatory damages on, individuals who are only to a small degree responsible for the relevant outcomes, and I doubt these implications will accord with the intuitions of most. Perhaps C\&H would be be willing to embrace these radical implications. Prevailing criminal and tort law practices are, after all, controversial. It would be interesting to know their thoughts on this.

There is, admittedly, one important difference between most criminal and tort casesincluding my asbestos example - and the sorts of healthcare cases that $\mathrm{C} \& \mathrm{H}$ have in mind. Torts and crimes are typically clearly morally wrong, whereas, as C\&H note, the sorts of lifestyles that lead to disease are, in most cases, not obviously wrong. However, C\&H largely set aside this issue in their discussion. ${ }^{6}$ Their core arguments against responsibility for disease, and against responsibility-sensitive healthcare policies, are based on factors independent of the the (perceived) wrongness of the health-risking choices and lifestyles, and it is these independent factors (C\&H's Conditions 1-4) that, I think, generate unattractive implications for criminal and tort law.

\section{The Argument for Responsibility-Sensitive Healthcare Funding}

My third worry is that $\mathrm{C} \& \mathrm{H}$ undersell the principled argument in favour of responsibilitysensitive approaches to healthcare funding by failing to acknowledge the main virtue of such policies: someone has to bear the costs of healthcare, and, other things being equal, it is better that costs are borne by those more responsible for creating those costs than by those who are less responsible.

Consider a case in which, notwithstanding C\&H's arguments, we would think that a patient bears a substantial degree of responsibility for acquiring an illness. Consider, for instance, a well-educated and wealthy individual who, as an adult, makes the deliberate and well-informed decision that he would prefer to live a short life filled with gustutory and bodily pleasures than a longer but less fullsome life. He embarks on a life of copious consumption of rich food and fine wine, and after a dozen years of this, develops Type 2 diabetes as a result. This patient - call him the Bon Vivant-now requires an expensive treatment-dialysis for diabetic kidney disease, say. ${ }^{7}$

Let us suppose that the Bon Vivant is significantly responsible for his diabetic kidney disease, as I think even $\mathrm{C} \& \mathrm{H}$ would concede. The situation, then, is this: someone has to foot the bill for his dialysis, if he is going to receive it. The most salient alternatives are: (i) he bears the bill himself, or (ii) the bill is transferred to taxpayers (or, in countries with a social insurance system of healthcare, to those who pay compulsory health insurance premiums). Imposing costs on taxpayers has the advantage of allowing those costs to be spread thinly and more evenly across people and across time, but in a case where the patient is significantly 
responsible for his condition, as in this one, it also has the disadvantage of imposing the costs on individuals who are less responsible for it (taxpayers) rather than individuals who are more responsible (the patient). Indeed, some of the taxpayers who are required to contribute to the costs of this treatment will be precisely the faultlessly socially disadvantaged individuals whom $\mathrm{C} \& \mathrm{H}$ are most concerned to protect.

This, it seems to me, gives us a principled reason - though not a conclusive reasonto leave at least some of the costs of dialysis with our Bon Vivant.

Note that this argument does not require holding that the Bon Vivant positively deserves, in any absolute sense, to be sick, or to bear the financial costs of his dialysis. Nor does it require us to hold that he ought to be punished or sanctioned for his health-risking behaviour. All it requires us to hold is that the costs will be more deserved (or even just less undeserved) if imposed on him than if imposed on those who will otherwise bear them, or that he is more liable to bear those costs than those others. Put crudely, it's not that leaving the Bon Vivant to bear (some of) the costs of his healthcare would be positively good, just that it would be less bad, in one respect, than the alternative.

Note also that this argument can be extended to cases in which a patient's degree of responsibility for her illness is quite low. All it requires is that the patient is more responsible for it than those who will otherwise bear the cost.

Of course, none of this implies that we should - when all is said and done - reform our health systems so as to deny public funding to individuals like our imagined Bon Vivant. As I said at the outset, I concur with the view that we should not. That's in part because, as mentioned above, non-responsibility-sensitive funding policies have the advantage of spreading costs more thinly and evenly. It's also in part because considerations of responsibility would, in my view, at best justify only a relatively minor reduction of funding for those deemed responsible, and the moral benefits of implementing such minor reductions would, I think, be outweighed by the practical barriers to responsibility-sensitive healthcare funding. These are, as $\mathrm{C} \& \mathrm{H}$ highlight in Section 4 of their article, immense. 


\section{References}

${ }^{1}$ Clavien C, Hurst S. The undeserving sick? An evaluation of patients' responsibility for their health condition. Cambridge Quarterly of Healthcare Ethics. [ - DETAILS TO BE SUPPLIED ONCE ISSUE AND PAGINATION IS SET.]

${ }^{2}$ For the classic philosophical discussion of this episode, see Bennett J. The conscience of Huckleberry Finn. Philosophy 1974:49(188):123-134.

${ }^{3}$ For a systematic defence of this view, see Arpaly N. Unprincipled Virtue: An Inquiry Into Moral Agency. New York: Oxford University Press, 2003.

${ }^{4}$ McCulloch J. Tweedale G. Defending the Indefensible: The Global Asbestos Industry and Its Fight for Survival Oxford: Oxford University Press, 2008.

${ }^{5}$ Thomas Douglas and Laura Van den Borre. Asbestos neglect: Why asbestos exposure deserves greater policy attention. Health Policy 2019:123(5):516-9.

${ }^{6}$ For a critique of responsibility-sensitive healthcare funding that gives greater importance to the dubious moral wrongness of health-risking lifestyles, see Brown RCH, Maslen H, Savulescu J. Against moral responsibilisation of health: Prudential responsibility and health promotion. Public Health Ethics 2019:12(2):114-29.

${ }^{7}$ The example is inspired by one offered in Savulescu J. The present-aim theory: A submaximizing theory of reasons? Australasian Journal of Philosophy 1998:76(2):229-43, at 230. 